\title{
Histórias da nossa história: o acervo de José Honório Rodrigues*
}

\author{
Histories of our history: \\ José Honório Rodrigues's archieve
}

Luciano Aronne de Abreu**

Resumo: Este estudo objetiva tecer algumas considerações sobre a organização do acervo de José Honório Rodrigues, que se encontra sob a guarda do Espaço de Documentação e Memória Cultural Delfos, da PUCRS, além de fazer breves indicações sobre o seu conteúdo e potencialidades de pesquisa. O acervo foi classificado em 7 categorias: Governos Militares/Militarismo; Relações Internacionais; Holandeses; Judeus; Brasil Império; História/Historiografia/ Patrimônio e Arte; e Assuntos Gerais.

Palavras-chave: José Honório Rodrigues, História, Historiografia

\begin{abstract}
This study makes some observations on the work of organization of archives belonging to José Honório Rodrigues. Part of these archives are maintend by Delfos Documentation and Cultural Memory Center, at PUCRS. Besides the paper gives some indications about its content and research potentialities. This archive was classified in 7 categories: Military Government/Militarism; International Relations; the Dutch; the Jewish; Imperial Brazil; History/Historiography/Patrimony and Art; and General Subjects.
\end{abstract}

Keywords: José Honório Rodrigues, History, Historiography

* A escrita deste texto contou com a colaboração da acadêmica do curso de História da PUCRS, Amanda Araújo de Araújo, bolsista de iniciação científica do projeto "Histórias da Nossa História: o Acervo de José Honório Rodrigues".

** Professor do curso de História e do Programa de Pós-Graduação em História da PUCRS. Doutor em História Latino-Americana pela UNISINOS. E-mail: <luciano. abreu@pucrs.br>. 
José Honório Rodrigues (1913-1987)ํㅜ que se definiria historiador por vocação, é reconhecido por seus colegas de profissão como uma espécie de "pai da historiografia brasileira", pioneiro nos estudos teóricos e estudioso da história da história do Brasil2 ${ }^{2}$. A esse respeito, José de Assunção Barros destaca que a contribuição de José Honório Rodrigues (JHR) para a formação de historiadores deixou traços firmes na historiografia brasileira, visto que esta não foi uma preocupação comum entre os historiadores brasileiros até recentemente, a não ser em estudos pontuais de Capistrano de Abreu e de Oliveira Lima. Em suas palavras, diz Barros: "um esforço sistemático de produzir uma abrangente análise historiográfica brasileira, como o que foi empreendido pelo historiador carioca, é certamente uma jóia rara até tempos mais recentes" (Barros, s/d: 3).

Ainda assim, ao contrário do que acontece com outros grandes historiadores de sua geração, como, por exemplo, os chamados "intérpretes do Brasil" - Gilberto Freyre, Sérgio Buarque de Holanda, Caio Prado Júnior, Nelson Werneck Sodré, Celso Furtado e Raimundo Faoro - a obra de JHR tem sido pouco estudada e difundida entre as novas gerações de historiadores e de estudantes de história. Sobre esses autores e suas obras, José Otávio de Arruda Mello observa que seria algo ingênuo situar algum deles "como o maior, tal a amplitude da contribuição que, de diferentes ângulos, eles perfizeram. Um deles, todavia, fez-se única e exclusivamente historiador" - José Honório Rodrigues (Mello, 1994: 145).

1 José Honório Rodrigues nasceu em 20 de setembro de 1913, no Rio de Janeiro, filho de Dona Judith e de Honório José Rodrigues. Em 1933 ingressou na Faculdade de Direito do Rio de Janeiro, mais tarde transferindo-se para a Faculdade Nacional de Direito da Universidade do Brasil. Aos 24 anos, além de concluir sua formação jurídica, conquistou também o Prêmio de Erudição da Academia Brasileira de Letras com o trabalho "A Civilização Holandesa no Brasil", que, em 1940, seria publicado como seu primeiro livro. Em 1943, JHR foi contemplado com uma bolsa de estudos da Fundação Rockfeller, levando-o a passar uma temporada nos EUA, o que marcaria de forma significativa sua formação de historiador e o influenciaria a realizar seus estudos pioneiros nas áreas de teoria, metodologia e historiografia no Brasil. Já nos anos 50, ganhou uma nova bolsa de estudos, dessa vez do Conselho Britânico, e realizou cursos na Escola Superior de Guerra (1955), o que contribuiu para dar novos rumos à sua obra de historiador, mais preocupada com questões do presente e suas relações com o passado, o que José Otávio de Arruda Mello definiria como "história combatente", participante. Dentre outros tantos cargos de professor e pesquisador exercidos ao longo de sua vida profissional, JHR foi também diretor do Instituto Rio Branco e do Arquivo Nacional. Em 1969 foi eleito para a cadeira $\mathrm{n}^{\circ} 35$ da Academia Brasileira de Letras. Faleceu no Rio de Janeiro, em 1987, meses após sofrer uma isquemia cerebral.

2 A respeito da obra de José Honório Rodrigues, uma ampla avaliação pode ser encontrada em: GLEZER, Raquel. O Fazer e o Saber na obra de José Honório Rodrigues: um modelo de análise historiográfica. São Paulo: USP, 1976. 
Talvez se possa especular que essa situação se deva especialmente a três fatores conjugados: a) as amplas e profundas mudanças ocorridas no campo da história, desde fins dos anos 80 até hoje, que teriam levado ao "esquecimento" algumas das principais obras de JHR sobre teoria, metodologia e historiografia da História; b) a inexistência de uma tradição de estudos historiográficos no Brasil, temática que concentra algumas das principais contribuições de JHR aos estudos históricos, o que não teria estimulado muitos historiadores a estudarem sua obra; c) a controvérsia a respeito da doação do acervo José Honório Rodrigues (AJHR) e as conseqüentes restrições daí advindas para o seu acesso à pesquisa. Atualmente, porém, deve-se ressaltar que este acervo se encontra sob a guarda do Instituto de Estudos Brasileiros (IEB), da Universidade de São Paulo (USP) e, uma pequena parcela, no DELFOS - Espaço de Documentação e Memória Cultural, da Pontifícia Universidade Católica do Rio Grande do Sul (PUCRS), ambos com livre acesso aos pesquisadores.

Nesse momento, porém, não pretendemos avançar na análise de tais especulações, nem exatamente realizar um estudo historiográfico sobre a obra de JHR, mas tão somente tecer algumas breves considerações sobre o trabalho de organização da parcela do seu acervo que se encontra sob a guarda da PUCRS, e fazer algumas também breves indicações sobre o seu conteúdo e potencialidades de pesquisa.

\section{O acervo e sua organização}

Em primeiro lugar, deve-se observar que o trabalho de organização de um acervo principia sempre pela busca de informações a respeito de sua própria história, o que é essencial à correta avaliação de historiadores ou arquivistas a respeito de sua integridade, condições de conservação e dos critérios de organização e catalogação a serem adotados. No caso do AJHR, porém, pouco se sabe a respeito de sua história, a não ser por informações esparsas encontradas em algumas bibliografias ou mesmo em alguns documentos que dele fazem parte.

Quanto às informações bibliográficas, por exemplo, Raquel Glezer nos informa em sua tese que JHR dava preferência em suas pesquisas aos materiais impressos - anais, atas, periódicos, legislações e obras publicadas - tendo consultado documentos manuscritos em apenas dois de seus trabalhos: "Brasil e África: outro horizonte" e "A Assembléia Constituinte de 1823". Sobre o volume de suas publicações, Glezer contabilizou um total de 1053 documentos editados, sendo $87 \%$ em 
periódicos em 13\% em publicações autônomas (livros). A esse respeito, José Otávio Arruda de Mello diz que tal volume se deveu

ao caráter metódico do historiador que, onde quer que estivesse, recolhia material de revistas e jornais para organização de pastas, sobre as quais trabalhava em geral de manhã. As tardes normalmente eram reservadas a pesquisas e compromissos sócio-culturais na cidade, e as noites a telefonemas, leitura de jornais, programas de televisão. [...] Essa metodologia de trabalho, algo sistemática, conjugou-se com a coerência do autor, conferindo unidade à sua produção (Mello, 1994: 183).

Além de tais informações, de caráter mais genérico, encontram-se no próprio acervo documentos que nos informam sobre seu conteúdo mais de 300 pastas, microfilmes, fotografias, originais do autor, textos de jornais, objetos, móveis e cerca de 25 mil livros. Nesse sentido, podemse consultar os próprios originais do documento intitulado "Protocolo de Intenções - Doação da 'Coleção José Honório Rodrigues' ao Instituto de Estudos Avançados da Universidade de São Paulo por Leda Boechat Rodrigues" (AJHR T 0070). De igual forma, estes mesmos documentos nos dão também pistas sobre a controvérsia acima referida, sobre a doação inicial do acervo de JHR ao Instituto de Estudos Avançados (IEA), da Universidade de São Paulo (USP).

De sua parte, a $\mathrm{Sr}^{\mathrm{a}}$. Leda se manifestaria descontente com o cuidado e o tratamento dispensados ao acervo por ela doado ao IEA (AJHR T 0070); por outro lado, ao menos na parcela do acervo JHR que atualmente se encontra sob a guarda do Delfos, não encontramos a esse respeito nenhuma manifestação ou resposta do Instituto à viúva. Ainda assim, deve-se observar que algumas pastas do AJHR contêm materiais timbrados do IEA, o que evidencia o início do seu trabalho de higienização e catalogação da documentação então recebida em doação. De todo modo, ainda que fisicamente a maior parte do seu conteúdo já tivesse sido encaminhada para o IEA, depreende-se dos documentos acima citados que a assinatura da doação oficial do acervo JHR à USP não teria ocorrido naquele momento, de forma imediata. Não sabemos com segurança a continuação e os meandros dessa história, apenas o seu final, que resultou na atual guarda do acervo JHR pelo IEB (www.ieb. usp.br), e não mais pelo IEA, e pelo Delfos (www.pucrs.br/delfos), sendo que os documentos de posse deste último não foram doados diretamente pela $\mathrm{Sr}^{\mathrm{a}}$. Leda, mas pelo historiador Ricardo Seitenfus, por ela referido em pelo menos um dos documentos da já citada controvérsia. 
A seguir, após tais referências de ordem mais geral, devem-se então considerar algumas questões mais específicas sobre os documentos e as condições de organização e catalogação do acervo JHR doado em 2008 ao Delfos. A esse respeito, além de suas condições bastante ruins de conservação - umidade, folhas roídas por ratos e traças e documentos incompletos ou misturados - deve-se ainda destacar duas outras importantes questões: alguns dos seus documentos, como acima já referido, haviam passado por um processo inicial de catalogação na USP, estando ainda hoje guardados em pastas timbradas do IEA; outros, no entanto, claramente não haviam pertencido a JHR, mas a Ricardo Seitenfus, tendo sido misturados ao longo do tempo.

Nessas condições, embora esse tenha sido um princípio básico do trabalho de catalogação e arquivamento do acervo JHR, nem sempre foi possível restituir a organização supostamente original dos documentos em suas respectivas pastas e envelopes. Além das dificuldades já referidas à adoção desse princípio, deve-se ainda apontar o caráter lacunar do acervo recebido pelo Delfos, sem que se saiba exatamente se esta parte do acervo e aquela sob a guarda do IEB têm documentos complementares entre si, ou se são totalmente distintas. Ainda assim, com base em possíveis evidências encontradas nos próprios documentos - paginação, data e seqüência textual, por exemplo - e em indicações bibliográficas esparsas, como a referência já citada de Mello, de que JHR organizava metodicamente recortes de jornais e revistas (e outras notas) em pastas temáticas, buscamos minimamente nos aproximar do que supomos ter sido a lógica de organização do referido acervo.

Das mais de 300 pastas que teriam sido doadas inicialmente à USP, cerca de 100 delas encontram-se hoje no Delfos. Ou estas e aquelas seriam diferentes? Impossível saber com certeza, mas o mais importante é destacar que os documentos nelas existentes são do mesmo tipo daqueles que fazem parte do conjunto doado à Universidade de São Paulo e que Glezer diz terem sido os preferidos por JHR em seus estudos - anais, atas, periódicos e legislações. Não foi recebida pelo Delfos a doação de microfilmes, objetos ou móveis, nem de qualquer parte da biblioteca pessoal de JHR; fotos há apenas uma ou outra soltas em meio aos demais documentos escritos.

Em termos práticos, após a etapa de higienização do acervo, seus documentos foram organizados em pastas temáticas do tipo "Dossiê", visto que o próprio JHR reunia num mesmo conjunto diferentes tipos de fontes pertinentes a um determinado assunto. Por exemplo, ao longo de suas pesquisas sobre as invasões holandesas no Brasil, o historiador 
José Honório Rodrigues coletou todo tipo de fontes e referências sobre o tema, desde indicações de documentos de arquivos nacionais e estrangeiros até bibliografias, passando também por notas biográficas dos seus personagens e notícias contemporâneas de jornais variados sobre a Holanda e os holandeses. Desse modo, o estudioso da obra de JHR poderá encontrar numa mesma pasta desde notas sobre fontes do século XVII até recortes de jornais de fins do século XX, subdivididos em envelopes confeccionados e titulados pelo próprio historiador. A organização, portanto, do acervo JHR em pastas do tipo "Dossiê" baseou-se no princípio já referido de respeitar, sempre que possível, sua lógica e ordem supostamente originais.

Em tais pastas, para cada um dos seus itens documentais, foi organizado um "inventário sumário", o qual se encontra disponível no site da biblioteca central da PUCRS (www.pucrs.br/delfos), contendo as seguintes informações: assunto, data, tipo de documento, breve resumo e observações. Por fim, deve-se ainda referir que as cerca de 100 pastas do acervo JHR guardadas no Delfos foram agrupadas nas seguintes categorias: Governos Militares/Militarismo; Relações Internacionais; Holandeses; Judeus; Brasil Império; História/Historiografia/Patrimônio e Arte; e Assuntos Gerais, cujos conteúdos e possibilidades de pesquisa veremos a seguir.

\section{$O$ acervo e a pesquisa}

Ainda que José Honório Rodrigues tenha ficado conhecido, como já referimos, como uma espécie de "pai da historiografia brasileira", por seu pioneirismo nos estudos de teoria e historiografia brasileira, deve-se aqui observar que suas obras abrangem também outros tantos temas essenciais à compreensão da história do Brasil, desde as invasões holandesas até as relações internacionais do país, desde o século XVII até fins do século XX. Tal variedade e amplitude de sua produção, que até o ano de 1975 foi contabilizada por Glezer em 1053 documentos editados (1976: 19), pode ser atribuída não só ao caráter metódico de JHR, como já citado, mas também aos variados cargos por ele exercidos ao longo de sua vida como historiador e, talvez, à sua própria concepção "revisionista e combatente" da história, como diz Mello.

Sobre tal concepção de história, em suas próprias palavras, diz JHR: o objetivo da história é dar sentido ao passado, "é conhecer e compreender não para contemplar um passado morto, mas para agir, para libertar consciências, para dar força às forças do progresso, para 
identificar e integrar o país todo com sua história e seu futuro, essa é toda a tarefa da história" (In: Mello, 1994: 150). Quanto às suas várias atividades de historiador, desenvolvidas em diferentes momentos de sua vida junto ao Instituto do Açúcar e do Álcool, Instituto Nacional do Livro, Biblioteca Nacional, Instituto Rio Branco, Itamaraty, Arquivo Nacional e como professor visitante em universidades da Inglaterra e dos Estados Unidos, Glezer e Mello ${ }^{3}$ estão de acordo em associá-las diretamente às mudanças de enfoque e à variedade de sua produção historiográfica.

Sua obra de estreia, por exemplo - "Civilização Holandesa no Brasil" (1940) - que em 1937 havia sido vencedora do Prêmio de Erudição da Academia Brasileira de Letras, corresponde a uma fase em que "o açúcar constituiu uma predileção honoriana, para quem as raízes do Brasil encontram-se no nordeste e não em São Paulo, 'bugre até o século XVIII"” (Mello, 1994: 163). Nessa época, coincidência ou não, o historiador viria a desempenhar sua primeira função pública como bibliotecário do Instituto do Açúcar e do Álcool (1945), então presidido por Barbosa Lima Sobrinho (Glezer, 1976: 96).

Já entre os anos de 1946 e 1958, como Diretor de Obras Raras e Publicações da Biblioteca Nacional, de acordo com Francisco Iglesias, JHR seria responsável por tornar acessíveis obras até então de difícil acesso. O mesmo se daria quando de sua passagem como Diretor do Arquivo Nacional (1958-64), preocupando-se também com a publicação de fontes e a adoção de reformas e cursos de formação de pessoal, inclusive trazendo ao Brasil T. R. Schellenberg, então a maior autoridade mundial em arquivística (Mello, 1994: 165).

Nessa mesma época, JHR seria ainda nomeado Encarregado de Pesquisas do Instituto Rio Branco (1949), onde começaria a atuar como professor a partir de 1953, manifestando então sua predileção por temas de relações internacionais. Tal predileção seria ampliada a partir dos anos 60 , motivada por dois outros fatores: a relação bastante próxima que JHR manteve com os chamados brasilianistas - historiadores estrangeiros que se preocupavam cada vez mais em estudar o Brasil, e sua oposição pessoal à política externa dos regimes militares, de franco alinhamento com os Estados Unidos. Daí decorrem, segundo Mello, as seguintes obras: "Capítulos das Relações Internacionais do Brasill";

Poucos são os estudos sistemáticos sobre a obra de José Honório Rodrigues. Dentre os mais importantes incluem-se os de Raquel Glezer, "O Fazer e o Saber na Obra de José Honório Rodrigues: um modelo de análise historiográfica", tese defendida na USP (1976), e de José Otávio de Arruda Mello, "Revisão e Combate no Grupo José Honório Rodrigues", que faz parte de obra organizada em conjunto pelo autor e por Leda Boechat Rodrigues (1994). 
"Brasil e África: Outro Horizonte e Interesse Nacional"; e "Interesse Nacional e Política Externa" (1994: 159; 177).

Por fim, sem pretendermos ser exaustivos ou deterministas nas relações ora estabelecidas entre obras publicadas e funções desempenhadas por JHR, devemos citar ainda duas outras importantes influências em sua produção de historiador: sua passagem pelos Estados Unidos, como bolsista da Fundação Rockfeller (1948), e o curso por ele realizado na Escola Superior de Guerra do Estado Maior das Forças Armadas (ESG) (1955).

No primeiro caso, na opinião de Glezer, ainda que José Honório Rodrigues exercesse suas atividades paralelamente à existência de cursos de formação de historiadores profissionais, ele próprio teria sido formado no período anterior à existência destes, só recebendo formação específica de historiador em cursos realizados nos Estados Unidos, quando teria então despertado para a importância do estudo de questões de teoria, metodologia e historiografia (1976: 85). Nesse mesmo sentido, Mello diz que JHR teria voltado dos Estados Unidos com a ideia de escrever uma obra seriada, com um livro dedicado a questões de teoria - "Teoria da História do Brasil", outro voltado à pesquisa histórica - "A Pesquisa Histórica no Brasil”, e uma série de caráter historiográfico, em vários volumes, os quais não chegaram a ser concluídos - "História da História do Brasil" (Mello, 1994: 159).

Quanto ao curso realizado na ESG, Glezer diz que este marcou o início de uma nova fase nos estudos de JHR, cujas obras passaram a ter um caráter mais analítico e menos descritivo (1976: 85). Em sentido semelhante, ainda que em outros termos, Mello diz que após esse curso José Honório mudou sua face de um "historiador erudito" para um "historiador participante", mas sem perder a erudição. A seu ver, a obra "Conciliação e Reforma no Brasil" seria a mais representativa dessa fase, na qual o autor se situa na linha de frente contra o "generalismo autoritário" (1994: 166-171).

Diante de uma produção historiográfica tão vasta e variada, como exemplificamos acima, Mello sugere aos estudiosos interessados em conhecer a obra de José Honório Rodrigues que principiem pela leitura da trilogia "Teoria e História do Brasil", "A Pesquisa Histórica no Brasil" e "História da História do Brasil", acrescentando a seguir os livros da trilogia de ideias histórico-políticas: "Aspirações Nacionais", "Conciliação e Reforma no Brasil" e "Interesse Nacional e Política Externa". Aos que quiserem aprofundar seus conhecimentos da obra honoriana, Mello sugere ainda mais uma trilogia, que resume suas ideias 
de historiador, ou sua visão de História - "Vida e História", "História e Historiadores do Brasil" e "História e Historiografia" (Mello, 1994: 202204). A estes mesmos estudiosos, ou ao menos àqueles que desejarem dar continuidade aos estudos pioneiros de José Honório Rodrigues sobre historiografia brasileira, tomando sua própria obra como objeto de pesquisa, sugerimos finalmente que se dediquem a um criterioso estudo dos documentos que constituem o chamado acervo JHR, atualmente sob a guarda do IEB (USP) e do Delfos (PUCRS), como já referido.

Nesse sentido, ressalvado o caráter lacunar da parcela do acervo recebida pelo Delfos, sua própria forma de organização e os tipos de documentos que dele fazem parte podem já se constituir em indicativos, ainda que preliminares, dos métodos de trabalho do historiador José Honório Rodrigues, sempre preocupado em coletar a maior quantidade e variedade possível de dados sobre os seus objetos de estudo, os quais eram reunidos em envelopes temáticos por ele mesmo confeccionados. Tal era a sua obsessão a esse respeito que, certa vez, chegou a confessar ao seu amigo e também historiador, padre Serafim Leite, ter dificuldade em parar de pesquisar e começar a escrever, ao que este teria respondido: "Não tente esgotar o assunto do seu trabalho. Deixe algo para os que vierem depois de si. Quando sentir que o material recolhido já lhe permite escrever, encerre a pesquisa e comece a redação" (Rodrigues, 1994: 124). Além disso, pode-se também afirmar que as diferentes categorias em que foi dividido o acervo JHR do Delfos são igualmente representativas da variedade de temas pelos quais vimos que esse historiador se interessou ao longo de sua carreira. Apenas a título de exemplo, portanto, faremos algumas breves referências ao conteúdo documental de cada uma delas, com especial ênfase às categorias "Holandeses" e "Relações Internacionais", que concentram a maior parte e os mais importantes documentos do acervo referido.

A categoria "Governos Militares/Militarismo" reúne centenas de recortes de jornais e revistas variados, entre as décadas de 1950 e 1970, que abordam questões como treinamento dos militares, regulamentação da carreira militar, notas sobre os governos de Castelo Branco, Costa e Silva e Médici, desenvolvimento econômico brasileiro, indústria bélica e ditadura militar na África, os quais são reunidos, por exemplo, em envelopes com os seguintes títulos: "Militarismo (1966)"; "Militarismo (1967)"; "Militarismo (1968)"; "Militarismo (1969)"; "Militarismo (1970)"; "Militares (1970)"; "Militares (1973 e 1974)"; "Militares (1975, 1976, 1977 e 1978)"; “África - Golpes Militares década de 60"; e "Governo Médici (política nacional)". 
Em "Relações Internacionais", além de muitos recortes de jornais e revistas (décadas de 1950 a 1980), encontram-se também alguns artigos impressos e anotações manuscritas de JHR sobre questões relativas à política externa de Juscelino Kubitscheck, relações externas do Brasil (especialmente com Estados Unidos, França, Rússia, África e América Latina), OTAN, ONU, armas atômicas, Fidel Castro e John Kennedy.

Dentre estes, destacamos especialmente os originais datilografados do "Curso de Relações Internacionais", ministrado por José Honório Rodrigues no Itamarati, em 1956, totalizando mais de 200 páginas. Além do seu conteúdo e das correções manuscritas feitas pelo próprio autor, que por si só já justificariam a atenção de pesquisadores interessados em estudos de historiografia brasileira ou de crítica genética, este texto se destaca também por sua inusitada trajetória, a qual é relatada em sua folha de rosto por Leda Boechat Rodrigues (LBR), após a morte de JHR. Em suas palavras, diz ela:

Título sugerido por Paulo Sérgio Pinheiro.

Em 1957 JHR pediu a José Ant ${ }^{\circ}$. Soares de Souza para ler as apostilas do curso que deu em 1956 no Itamarati.

José Antônio apontou erros e a inversão de 2 capítulos. Aconselhou José Honório a não publicar antes de preencher as lacunas existentes, na sua opinião.

Em dezembro de 1986, já hemiplégico e sem fala, recebeu carta da Ática, perguntando se ele teria algo para ela. José Honório decidiu mandar como livro o texto das apostilas de 1956, sem mexer no que ficara na gaveta desde 1957.

A Ática recebeu os originais deste 'livro' e da 'Introdução à História do Açúcar no Brasil' e depois de algum tempo devolveu-os pelo correio sem qualquer explicação escrita ou oral.

O Embaixador Hélio Cabral esteve com estes originais; constrangida pedi-lhe a devolução dos mesmos pelo telefone dia 17/08 e ele veio ao meu apartamento entregá-los, muito queixoso e desapontado.

Agora, em SP, darei palavra a Carlos Guilherme Mota e Ricardo Seitenfus. Suas sugestões no momento e depois.

Aguardarei.

$18 / 8 / 91$

LBR (AJHR 30053)

Embora breve, pode-se dizer que este relato é bastante preciso em suas indicações aos pesquisadores sobre a história do já citado texto de JHR, que seria mais tarde revisado e ampliado por Ricardo Seitenfus, o qual viria a publicá-lo em 1995, em seu nome e no de José Honório, 
pela editora Civilização Brasileira, sob o título de "Uma História Diplomática do Brasil (1531-1945)". Neste caso particular, portanto, ao contrário do que é usual em estudos historiográficos ou de crítica genética, os eventuais estudiosos do acervo JHR poderão conhecer com maior precisão a história de sua última obra (póstuma), comparar suas correções e texto original, escrito na forma de um curso, com as revisões e acréscimos feitos cerca de 40 anos depois por Seitenfus, que deu ao texto sua forma final para publicação.

Nessa mesma categoria - "Relações Internacionais" - destacamos ainda os seguintes documentos: original datilografado do texto "O Novo Sentido da Política Exterior do Brasil", com o nome do autor e correções escritos à mão, em papel timbrado do Ministério da Justiça e Negócios Interiores (AJHR 29282); e volume encadernado sob o título "Arquivo Histórico (1967): Ministério das Relações Exteriores - Departamento de Administração - Arquivo Particular do Visconde de Cabo Frio" (AJHR 30007).

Já as categorias "Holandeses" e "Judeus", ainda que sejam evidentemente distintas, possuem importantes ligações entre si, visto que as primeiras referências de JHR aos judeus nos remetem ao período do domínio holandês no Brasil, embora não se limitem a ele, estendendo-se até os anos 1980 e referindo-se também à imigração israelita e à formação de congregações judaicas no país. São muitos os manuscritos de JHR sobre personagens do período holandês, bibliografias e referências de fontes e arquivos (brasileiros e estrangeiros) sobre essas duas temáticas, originais do autor (incompletos), textos impressos e vários exemplares da revista "Aonde Vamos?", que se define como um "semanário judaico independente do Brasil".

Em particular na categoria "Holandeses", pode-se perceber com clareza o já citado caráter metódico de JHR, que reunia todo tipo de fontes e referências sobre o tema em estudo em envelopes por ele mesmo confeccionados, os quais eram em geral divididos por eventos, regiões ou personagens. Nesse sentido, a título de exemplo, podem-se citar os títulos de alguns destes envelopes: "Relação e Guerra HolandaInglaterra"; "Holandeses na Amazônia"; "Invasões Holandesas cronologia"; História Holanda - século XVIII"; "Guiana Holandesa"; "Holandeses nos Estados Unidos"; "Matias de Albuquerque"; "Fco. Barreto"; "Grotius"; "Netscher/Nassau/Conde Olivares/Vidal Negreiros"; "Felipe Camarão"; e muitos outros.

Ainda sobre seu caráter metódico, outro exemplo interessante encontrado também na categoria "Holandeses" são os cadernos de 
anotações de JHR, que reuniam uma série de informações e observações do historiador sobre os arquivos por ele pesquisados e seus fundos, condições de conservação e características dos documentos e breves indicações de seu conteúdo. Um destes cadernos se intitula "Documentos Holandeses coligidos por José Higino", com o nome de JHR grafado logo abaixo, onde são por ele reunidas indicações dos documentos holandeses encontrados em arquivos de Pernambuco (AJHR 30771). Para que se tenha uma ideia mais clara a esse respeito, citamos abaixo uma breve nota encontrada em outro destes cadernos de JHR, intitulada "Documents sur les marranes d' Espagne et de Portugal sous Philiphe IV", onde se pode ler o seguinte:

Estes dois adquiridos recentemente em Madri provêm dos arquivos do Conselho da ING em Espanha. Formam uma coleção de 103 pastas, algumas trazendo a 'paraphe' de Ph IV.

1621 - sub de Ph IV cristãos passando para ESP para fugir da inquisição portuguesa.

1622 - 4.000 partiram para o estrangeiro (AJHR 30799).

Por fim, pode-se também encontrar nessa mesma categoria um minucioso planejamento de JHR para a escrita de um trabalho intitulado "Introdução ao Estudo da Influência Holandesa no Brasil", a ser dividido em 6 partes - "Problemas da Civilização Atlântica"; "O Plano Geográfico da Conquista"; "O Problema das Raças"; "A Sociedade (meio urbano)"; "A Sociedade (meio rural)"; e "O Espírito do Renascimento" - já com a indicação de cada uma de suas subdivisões (AJHR 30773).

Pode-se dizer, portanto, que tais documentos presentes na categoria "Holandeses" permitem ao estudioso da obra de José Honório Rodrigues demonstrar empiricamente o caráter metódico de cada uma das etapas do seu trabalho de historiador - pesquisa documental, crítica das fontes e escrita da história - o que pode de alguma forma auxiliar numa melhor compreensão e interpretação de suas obras sobre essa temática. Além disso, ainda que muitas dessas informações tenham sido publicadas na obra "Historiografia e Bibliografia do Domínio Holandês no Brasil" (1949), algumas pequenas notas ou indicações encontradas no acervo JHR podem ter permanecido inéditas, cabendo aos seus estudiosos identificá-las, o que poderia se constituir também em valiosas dicas aos novos historiadores interessados em estudar o período de domínio holandês no Brasil (1630-1654).

Quanto à categoria "Brasil Império", esta reúne muitos recortes de jornais, algumas fotografias e manuscritos de JHR com referências 
a personagens como Varnhagen e Barão do Rio Branco, além de cópias de documentos como as Atas das Sessões do Conselho de Estado. Em alguns casos, porém, como em relação ao já citado arquivo particular do Visconde de Cabo Frio, ainda que seus documentos se refiram aos tempos monárquicos, optamos por classificá-los na categoria "Relações Internacionais", devido ao seu conteúdo e por terem sido reunidos e publicados pelo Ministério das Relações Exteriores. Por outro lado, dentre os documentos efetivamente classificados na categoria "Brasil Império", merecem destaque aqueles relativos aos estudos de José Honório sobre Varnhagen, que reúnem desde uma única foto sobre a casa onde este teria nascido (AJHR 31116) até notas de pesquisa e textos escritos por JHR sobre o seu personagem. Quanto às notas, pode-se citar como exemplo o documento intitulado "Pesquisas de Varnhagen”, contendo várias páginas anotadas a lápis por José Honório Rodrigues, com referências e comentários às pesquisas desenvolvidas por Varnhagen quando em missão na Europa, em meados do século XIX (AJHR 31108). Já em relação aos textos, dois deles merecem destaque: o original datilografado de um estudo de JHR, escrito em espanhol, com o título "Francisco A. de Varnhagen (Miembro de la Universidad de Chile)" (AJHR 31116); e uma fotocópia de texto datilografado, com título escrito à mão, intitulado "Varnhagen: Primeiro Mestre da Historiografia Brasileira (1861-1878)", com correções e revisões manuais do historiador JHR (AJHR 31116). Por fim, pode-se também destacar dentre os documentos de "Brasil Império" um conjunto de 5 envelopes com mapas da campanha brasileira na Guerra do Paraguai, cujos títulos são exatamente "Guerra do Paraguai - Mapas de Campanha" (AJHR 0029.1 até 0029.5 )

Já as categorias "História/Historiografia/Patrimônio e Arte" e "Assuntos Gerais" têm em comum o fato de serem formadas por documentos esparsos, sem muita continuidade entre si, ainda que as questões que servem de título à primeira delas tenham se constituído numa espécie de "ponto de contato" entre os seus documentos constituintes - recortes de jornais, alguns manuscritos e textos impressos - que se referem a temas como história e imprensa, história e cinema, história moderna e contemporânea, O Continente do Rio Grande, historiografia nordestina, historiografia artística brasileira, patrimônio histórico e acervo do Rijksinstituut Museu, da Holanda. Em "Assuntos Gerais" encontram-se também alguns recortes de jornais e manuscritos sobre temas variados, como, por exemplo, Chile e Salvador Allende, Minas Gerais e reforma agrária. 
Enfim, apesar das suas já citadas limitações, pode-se afirmar que o acervo JHR do Delfos oferece boas referências aos estudiosos que desejarem realizar uma análise historiográfica da obra de José Honório Rodrigues, seja em relação aos seus métodos de trabalho ou, por exemplo, às suas opiniões e impressões pessoais a respeito de livros, acontecimentos históricos ou mesmo de sua própria época. Por fim, fica aqui o nosso desejo de que a ampliação e valorização crescentes dos estudos de historiografia entre os historiadores, aí incluídos muitos brasileiros, possam se constituir em estímulos para a ampliação dos estudos sobre a obra pioneira de José Honório.

\section{Referências}

BARROS, José D'Assunção. História e Historiografia: considerações sobre a obra de José Honório Rodrigues. Fênix Revista de História e Estudos Culturais, v. 5, ano V, n. 3 .

FRAIZ, Priscila Moraes Varella; COSTA, Célia Maria Leite. Como Organizar Arquivos Pessoais. São Paulo: 2001.

GLEZER, Raquel. O Fazer e o Saber na obra de José Honório Rodrigues: um modelo de análise historiográfica. São Paulo: USP, 1976.

IGLÉSIAS, Francisco. José Honório Rodrigues e a Historiografia Brasileira. Revista de Estudos Históricos, v. 1, n. 1, 1988.

LEITE, Marilena Paes. Arquivo: teoria e prática. Rio de Janeiro: Fundação Getúlio Vargas, 1994.

MOTA, Carlos Guilherme. José Honório Rodrigues: a obra inacabada. Estudos Avançados, USP.

RODRIGUES, Leda Boechat; MELLO, José Otávio de Arruda. José Honório Rodrigues: um historiador na trincheira. Rio de Janeiro: Civilização Brasileira, 1994.

RODRIGUES, José Honório. Civilização Holandesa no Brasil. São Paulo: Cia. Editora Nacional: 1940.

RODRIGUES, José Honório. Teoria da História do Brasil: introdução metodológica. São Paulo, IPE: 1949.

RODRIGUES, José Honório. A pesquisa histórica no Brasil. Rio de Janeiro: INL: 1952. RODRIGUES, José Honório. Conciliação e Reforma no Brasil: um desafio históricocultural. Rio de Janeiro: Civilização Brasileira: 1965.

RODRIGUES, José Honório. Interesse Nacional e Politica Externa. Rio de Janeiro: Civilização Brasileira: 1966.

RODRIGUES, José Honório. História e historiografia. Petrópolis: Vozes: 1970.

RODRIGUES, José Honório. História da História do Brasil. São Paulo: Cia. Editora Nacional: 1979. 